\title{
Relief of gene repression by Torso RTK signaling: role of capicua in Drosophila terminal and dorsoventral patterning
}

\author{
Gerardo Jiménez, ${ }^{1}$ Antoine Guichet, ${ }^{2}$ Anne Ephrussi, ${ }^{2}$ and Jordi Casanova ${ }^{1,3}$ \\ ${ }^{1}$ Institut de Biologia Molecular de Barcelona (CSIC), 08034 Barcelona, Spain; ${ }^{2}$ Developmental Biology Programme, European \\ Molecular Biology Laboratory, 69117 Heidelberg, Germany
}

\begin{abstract}
Differentiation of the embryonic termini in Drosophila depends on signaling by the Tor RTK, which induces terminal gene expression by inactivating at the embryonic poles a uniformly distributed repressor activity that involves the Gro corepressor. Here, we identify a new gene, cic, that acts as a repressor of terminal genes regulated by the Tor pathway. cic also mediates repression along the dorsoventral axis, a process that requires the Dorsal morphogen and Gro, and which is also inhibited by Tor signaling at the termini. cic encodes an HMG-box transcription factor that interacts with Gro in vitro. We present evidence that Tor signaling regulates terminal patterning by inactivating Cic at the embryo poles. cic has been evolutionarily conserved, suggesting that Cic-like proteins may act as repressors regulated by RTK signaling in other organisms.
\end{abstract}

[Key Words: Drosophila; RTK signaling; repression; capicua; groucho; torso]

Received August 3, 1999; revised version accepted December 1, 1999.

Signaling by receptor tyrosine kinases (RTKs) is an important mechanism linking extracellular signals (e.g., growth factors) to changes in gene expression and cell behavior. RTK signaling involves a pathway of transducing proteins including Ras, Raf, and mitogen-associated protein kinase (MAPK), which ultimately affects expression of target genes by phosphorylation of specific transcription factors. This transduction pathway has been highly conserved during evolution and controls multiple developmental processes in all animals. One such process that has been studied in detail is the development of terminal structures (the anterior and posterior poles) of the Drosophila embryo (Duffy and Perrimon 1994). Terminal development requires a cascade of maternally acting genes including torso (tor), which encodes an RTK uniformly distributed along the plasma membrane of the early embryo. Tor activation occurs exclusively at the embryonic poles by a ligand produced locally through the action of the $f_{S}(1)$ Nasrat, $f_{S}(1)$ pole-hole, torso-like, and trunk genes (Duffy and Perrimon 1994).

Tor signaling proceeds via the Ras/Raf/MAPK pathway to regulate expression of the zygotic genes tailless (t11) and huckebein $(h k b)$, which are specifically expressed at each pole of the embryo (Duffy and Perrimon 1994, and references therein). These genes encode transcription factors that initiate the developmental programs leading to differentiation of head and tail structures. Recently, it has been shown that Tor signaling

${ }^{3}$ Corresponding author.

E-MAIL jcrbmc@cid.csic.es; FAX 34932045904. does not activate terminal gene expression directly; rather, it functions by antagonizing at the poles a uniformly distributed repressor activity, allowing other maternal factors to activate transcription locally (Rusch and Levine 1994; Liaw et al. 1995; Paroush et al. 1997). Evidence for this view comes from the identification of regulatory elements in the $t 11$ promoter (called tor response elements, tor-REs) that confer terminal-specific expression and that, when mutated, cause severe derepression of $t 11$ transcription (Liaw et al. 1995).

Additional evidence for the regulation of $t 11$ and $h k b$ by relief of repression derives from the role of the Groucho (Gro) corepressor in this process (Paroush et al. 1997). Gro is a nuclear WD-repeat protein that does not bind DNA but interacts with a variety of DNA-bound transcriptional repressors (Fisher and Caudy 1998; Parkhurst 1998). These associations recruit Gro to target promoters, bringing about transcriptional repression. Gro has been shown to participate in terminal development by restricting the expression of $t 11$ and $h k b$ to the embryonic termini: Embryos deprived of maternal Gro function show derepression of $t 11$ and $h k b$ toward the middle of the embryo (Paroush et al. 1997). Thus, it has been proposed that Gro forms part of a repressor complex specifically inactivated by Tor signaling at the embryo poles (Paroush et al. 1997). However, the specific target of Tor signal inhibition remains unknown.

Similarly, the identity of the factor(s) that recruit Gro to terminal promoters is uncertain. Several Gro partners have been identified to date, for example, Hairy, Runt, Engrailed, Dorsal, and dTCF/pangolin /Cavallo et al. 
1998; Fisher and Caudy 1998; Parkhurst 1998; Roose et al. 1998), but none of these proteins seem to play a role in terminal patterning. Also, previous studies identified two putative repressors of t1l, GAGA, and NTF-1/ Grainyhead, but there is no evidence that they function via Gro (Liaw et al. 1995; Paroush et al. 1997). Thus, it is thought that Gro is recruited to the $t 11$ and $h k b$ promoters by an as yet unknown repressor factor(s) (Paroush et al. 1997; Fisher and Caudy 1998; Parkhurst 1998).

In this work, we identify a novel gene, capicua (cic), that acts as a repressor of $t l l$ and $h k b$ expression. In addition, cic mediates ventral repression of the dorsally expressed gene zerknüllt (zen), a process that also requires Gro and the rel factor Dorsal, and which is also inhibited by Tor signaling at the embryonic termini. cic encodes a putative transcription factor with a DNAbinding domain of the HMG box class. The Cic protein interacts with Gro in vitro, suggesting that both factors function in the same protein complex. Evidence is presented that Cic is the target inhibited by the Tor signal at the embryonic poles. Finally, Cic has been conserved during evolution, suggesting that Cic-like proteins may also function in repressor processes regulated by RTK signaling in other species.

\section{Results and Discussion}

\section{Identification of cic, a novel maternal effect} mutation affecting terminal development

We isolated cic in a P-element screen for female sterile mutations affecting the anteroposterior pattern of embryos. Females homozygous for the cic mutation $\left(\mathrm{cic}^{1}\right)$ are fully viable and produce embryos that form head and tail structures but lack most of the segmented trunk (Fig. $1 \mathrm{~A}, \mathrm{~B}$; hence, the name capicua, the Catalan for headand-tail). Hereafter, we refer to embryos lacking maternal cic function as cic mutant embryos. The phenotype of $\mathrm{cic}^{1}$ mutant embryos is rather uniform: Most embryos (>80\%) retain only $1-3$ partial abdominal denticle belts at $25^{\circ} \mathrm{C}$, whereas the rest of the embryos do not show any signs of abdominal segmentation. This latter phenotype is shown by virtually all embryos from females carrying the cic $^{1}$ allele in trans with a deficiency of the region, suggesting that $\mathrm{cic}^{1}$ is a strong hypomorph. The $\mathrm{cic}^{1}$ phenotype is similar to that of embryos from females carrying dominant gain-of-function mutations in tor (tor ${ }^{\text {gof }}$; Klinger et al. 1988) and other components of the Tor RTK pathway (see Duffy and Perrimon 1994). These mutations cause constitutive Tor RTK signaling in all regions of the embryo, leading to ectopic tll and $h \mathrm{k} b$ expression, and the subsequent differentiation of the segmented trunk as terminal structures. However, the above results with deficiencies of the cic region indicate that $\mathrm{cic}^{1}$ is a recessive loss-of-function mutation (see legend to Fig. 1).

Given the similarities between the tor ${ }^{\text {gof }}$ and cic $^{1}$ phenotypes, we examined the expression patterns of $t 11$ and $h k b$ in $c^{1} c^{1}$ embryos. Expression of both genes expands toward the center of such embryos, predominantly in the
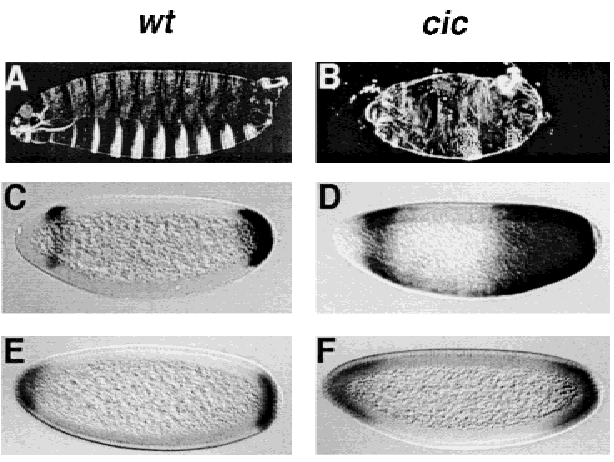

$h k b$

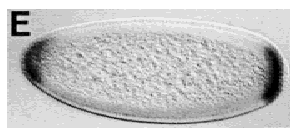

tor-RE-lacZ
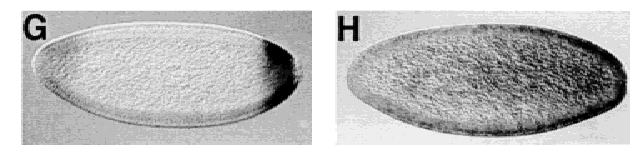

Figure 1. cic is required for repression of $t 11$ and $h k b$ during terminal development. Cuticle phenotypes of embryos derived from wild-type $(A)$ and homozygous $\operatorname{cic}^{1}(B)$ females. Note the strong suppression of trunk segmentation in the $\mathrm{cic}^{1}$ mutant embryo. Embryos from females carrying the cic $^{1}$ allele in trans with a deficiency of the cic region show a slightly more severe phenotype (not shown). (C-H) RNA expression patterns of $t 11$ $(C, D), h \mathrm{~kb}(E, F)$, and tor-RE-lacZ $(G, H)$ in embryos derived from wild-type $(C, E, G)$ and homozygous $\operatorname{cic}^{1}(D, F, H)$ females. Derepression is observed in all cases in $\mathrm{cic}^{1}$ mutant embryos. In this and following figures, anterior is to the left and dorsal is up.

posterior domain (Fig. 1C-F). The expanded expression of tll and $h \mathrm{~kb}$ is very similar to that observed in tor $^{\text {gof }}$ and gro mutant embryos (Weigel et al. 1990; Brunner et al. 1994; Paroush et al. 1997). We also analyzed the expression of a lacZ transgene under the control of a tor-RE from the $t 11$ promoter (see Introduction) that drives terminal-specific transcription (Liaw et al. 1995; construct G22) (Fig. 1G). In cic $^{1}$ mutant embryos, expression of this construct is derepressed toward the middle of the embryo (Fig. 1H). Together, these results suggest that the cic gene is normally required to restrict $t 11$ and $h k b$ expression to the embryonic poles.

cic could affect $t l l$ and $h k b$ expression by restricting Tor signaling to the embryonic poles (e.g., by limiting the domain of Tor receptor activation, or the domain of Tor signal transduction inside of the embryo). Alternatively, cic could function, like gro, as a repressor of $t l l$ and $h k b$ downstream of the Tor pathway. To help distinguish between these possibilities, we performed epistasis analyses using loss-of-function mutations in tor, Draf, and Dsor (encoding a Drosophila MEK, or MAPK kinase, homolog, Tsuda et al. 1993; see Fig. 2A), which normally cause a phenotype complementary to that of $\mathrm{cic}^{1}$, that is, absence of terminal structures. Embryos from females homozygous for $\mathrm{cic}^{1}$ and tor are identical to those from $\mathrm{cic}^{1}$ females alone (Fig. 2B). Likewise, $\mathrm{cic}^{1}$ females carrying loss-of-function clones of Draf or Dsor in the germ line produce embryos that display the cic phenotype (Fig. 2C). Thus, cic acts genetically downstream of Draf and Dsor. In addition, we examined directly the domain of Tor signal activity using a mono- 


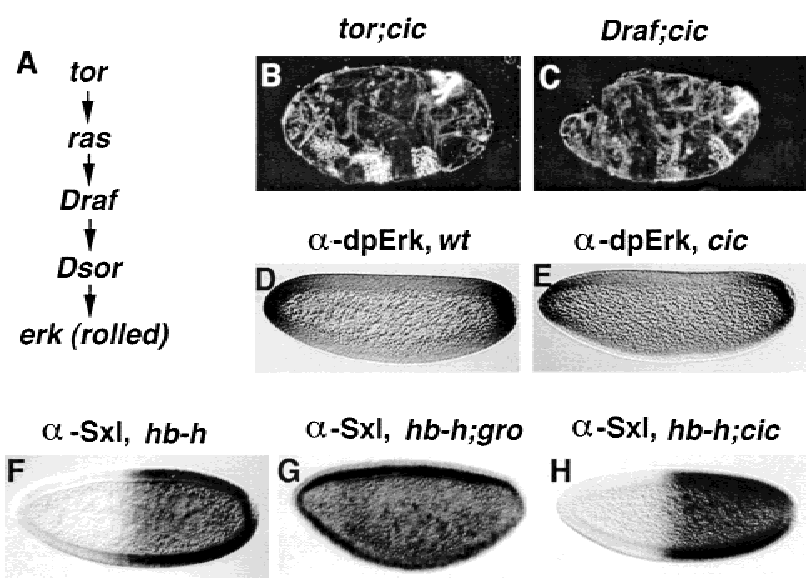

Figure 2. cic acts downstream of the Tor pathway and is not required for Gro activity. (A) Diagram of the Tor cascade. $(B, C)$ Cuticle phenotypes of embryos derived from doubly homozygous tor; cic females $(B)$ and from cic $^{1}$ females carrying germline clones of Draf $(C)$; the embryos display a cic-like phenotype, suggesting that cic acts downstream of Draf. The roles of cic, tor, and Draf in terminal patterning are strictly maternal and the mutations do not show paternal rescue. $(D, E)$ Antibody staining for activated Erk protein in wild-type $(D)$ and $\operatorname{cic}^{1}(E)$ embryos; the similar staining indicates that the domain of Tor signaling is unaffected in cic $^{1}$ mutant embryos. $(F-H)$ Effects on Sex-lethal (Sxl) expression of ectopic hairy (h) activity driven by the hunchback $(h b)$ promoter in otherwise wild-type $(F)$, gro ${ }^{E 48}$ $(G)$, and $\operatorname{cic}^{1}(H)$ embryos. Embryos were stained with an antibody against the active Sxl protein. Repression of Sxl by Hairy requires gro, however the Hairy/Gro complex does not require cic function.

clonal antibody against the active, diphosphorylated form of Drosophila MAPK (known as Erk; Brunner et al. 1994; Gabay et al. 1997), and found a normal pattern of Erk activation in cic $^{1}$ embryos (Fig. 2, cf. D and E). This shows that derepression of $t 11$ and $h k b$ in $c i c^{1}$ mutant embryos is not due to an expanded domain of Tor signaling, suggesting that cic is part of the activity that represses $t l l$ and $h k b$ in the central region of the embryo and is inhibited by Tor signaling at the embryonic poles.

The similar effects of cic and gro on terminal patterning raise the possibility that cic is necessary for Gro corepressor activity in general. However, two lines of evidence argue against this idea. First, Gro participates in many developmental processes, whereas the role of cic appears restricted to terminal and dorsoventral patterning (see below). Second, we have confirmed that Grodependent repression by Hairy in a sex determination assay (Paroush et al. 1994; Jiménez et al. 1997) does not require cic function (Fig. $2 \mathrm{~F}-\mathrm{H}$ ). These results indicate that cic does not generally affect Gro activity.

cic also affects repression along the dorsoventral axis of the embryo

Tor signaling at the embryo poles also regulates repressor processes that operate during dorsoventral patterning
(Casanova 1991; Rusch and Levine 1994). Such patterning depends on the Dorsal morphogen, a rel domain factor that accumulates in ventral nuclei of early embryos and acts as both an activator and repressor of transcription: It activates ventral-specific genes, for example, twist (twi), and represses dorsal-specific genes such as zen (see Rusch and Levine 1996; and references therein). Repression by Dorsal requires its association with Gro and other postulated corepressors that bind next to Dorsal in the zen promoter (Jiang et al. 1993; Kirov et al. 1993; Dubnicoff et al. 1997; Valentine et al. 1998; see below). This repressor complex is under negative regulation by Tor signaling at the embryonic termini, allowing zen expression at each pole of the embryo (Casanova 1991; Rusch and Levine 1994).

The mechanism of repression by Dorsal is not fully understood. Valentine et al. (1998) recently showed that Dead-Ringer (Dri) and Cut function as corepressors that assist Dorsal (and Gro) in its function as a repressor. However, the effects of removing either of these two factors appears weaker than those caused by the loss of Dorsal or Gro function, suggesting that other factors may also contribute to Dorsal repression. Because cic is involved in a Gro-mediated process that is inactivated by Tor signaling, we wondered if cic could also be involved in Dorsal repression. Consistent with this idea, zen expression is expanded ventrally in cic $^{1}$ mutant embryos (Fig. 3A,B). Although this expansion is not as strong as in dorsal or gro mutants, ectopic zen transcripts are clearly detected in lateral and ventral regions of the embryo, especially in its posterior half. In contrast, activation of twi by Dorsal is normal in $c^{1} c^{1}$ embryos (Fig. 3C,D), suggesting that cic only participates in repression, not activation, by Dorsal.

To test further the role of cic in ventral repression of zen, we analyzed a lacZ transgene carrying an evenskipped (eve) stripe 2 enhancer coupled to a silencer from the zen promoter, the zen Ventral Repression Element

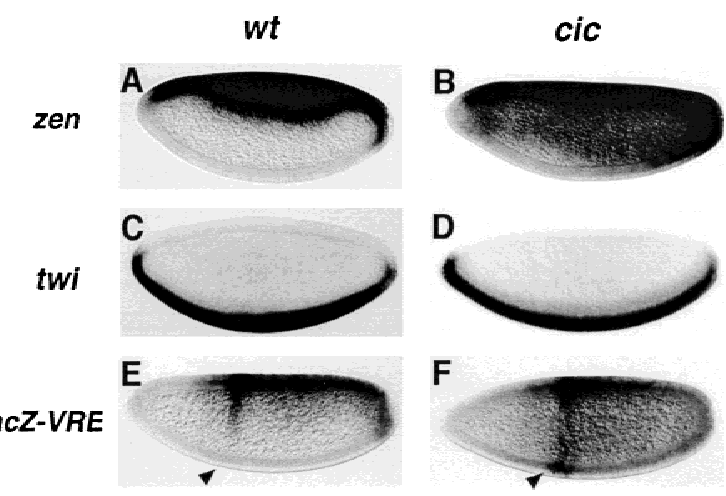

Figure 3. cic is required for repression of zen and acts through the VRE. RNA expression patterns of zen $(A, B), t w i(C, D)$, and St.2-lacZ-VRE $(E, F)$ in embryos derived from wild-type $(A, C, E)$ and homozygous $\operatorname{cic}^{1}(B, D, F)$ females. Derepression of zen and lac $Z$ expression driven by the eve stripe 2 enhancer (arrowhead) is observed in $\mathrm{cic}^{1}$ embryos. In contrast, the similar pattern of twi expression in wild-type and $\mathrm{cic}^{1}$ embryos indicates that activation of $t w i$ by Dorsal is independent of cic. 
(VRE), which includes binding sites for Dorsal and adjacent regulatory sites (Cai et al. 1996; see Materials and Methods). In wild-type embryos, lacZ expression directed by the eve stripe 2 enhancer is repressed ventrally by the VRE (Fig. 3E). This repression is clearly attenuated in cic $^{1}$ mutant embryos (Fig. $3 \mathrm{~F}$ ), permitting stripe 2 activation in the ventral-most side of the embryo. In addition, we observe significant ectopic lac $Z$ expression in ventral and lateral regions of the embryo, as expected if repression by Dorsal bound to the VRE is switched in favor of activation (Jiang et al. 1993; Kirov et al. 1993; Dubnicoff et al. 1997; Valentine et al. 1998). These results suggest that cic encodes one of the cofactors required for VRE activity and the conversion of Dorsal from an activator to a repressor of transcription. Because Dri and Cut also function as Dorsal corepressors, it appears that this role is shared by several factors with overlapping activities.

cic encodes an evolutionarily conserved HMG box protein

The $\mathrm{cic}^{1}$ mutation was recovered in a P-element screen, but it is not caused by the insertion of a functional $\mathrm{P}$ element. We therefore isolated the cic gene by positional cloning. We mapped cic to chromosomal position 92D1-2 using standard recombination and deficiency tests. We then searched for DNA polymorphisms in this region specific to the $\mathrm{cic}^{1}$ chromosome and found that the $\mathrm{cic}^{1}$ allele is associated with the insertion of a $1.5-\mathrm{kb}$ hobo transposon. This transposon maps $~ 300$ bp away from a previously described $\mathrm{P}$ element, $P(P Z) b w k^{8482}$, which causes the female sterile mutation bullwinkle (bwk, Rittenhouse and Berg 1995). P(PZ) bwk ${ }^{8482}$ produces a phenotype different from $\mathrm{cic}^{1}$ and complements $\mathrm{cic}^{1}$, indicating that the two mutations affect different genetic functions (see below).

The cic $^{1}$-specific hobo element is inserted in the $5^{\prime}$ untranslated region of a novel gene, which corresponds to EST clone LD05430 from the Berkeley Genome Project (Fig. 4A). Several lines of evidence confirm that this gene is cic. First, molecular analyses show that the hobo insertion disrupts the cic transcript (data not shown). Second, the $\operatorname{cic}^{1}$ mutation is not complemented by small deficiencies $(<500 \mathrm{bp})$ that span the hobo insertion site (Fig. 4A). Finally, we rescued the cic phenotype by Pelement transformation with a genomic fragment containing the cic gene (Fig. 4A). This fragment does not rescue the bwk phenotype, again showing that bwk and cic represent separate gene functions. Elucidation of the relationship between cic and $b w k$ at the molecular level will require the cloning of $b w k$.

We analyzed cic expression by in situ hybridization and found that cic mRNA is present at high levels in early blastoderm embryos (stage 1-3; Fig. 4B), consistent with a maternal expression of the gene. The cic transcripts decay rapidly so that they are barely detected by the onset of gastrulation (late stage 5; Fig. 4B) and at later stages of embryogenesis (not shown). These results, together with the strictly maternal effect character of the cic $^{1}$ mutation, argue that cic function is restricted to terminal and dorsoventral patterning of the early embryo.

Sequencing of cic cDNA clones shows that it encodes a putative transcription factor with a DNA-binding domain of the HMG box class (Fig. 4C). HMG box proteins are thought to function as architectural factors that induce bending of the target DNA and facilitate the assembly of multiprotein regulatory complexes at promoters (Grosschedl et al. 1994). The Cic HMG box domain contains several amino acid residues shared by a group of HMG box factors that bind sequence specifically to DNA, such as the LEF-1/TCF-1 factors, SRY, and the SRY-related Sox proteins (Grosschedl et al. 1994). Similarity searches against protein databases reveal that Cic defines a new subfamily within this group, which includes two related HMG box proteins from humans and Caenorhabditis elegans (Fig. 4D). The similarity between Cic and these proteins is particularly strong in the HMG box domain $175 \%$ and $67 \%$ identity with the human and $C$. elegans sequences, respectively), but also extends to other regions of the proteins (Fig. 4E), suggesting that they represent true orthologs.

\section{Cic interacts with Gro in vitro}

Our results indicate that Cic functions in two Gro-dependent repressor processes inactivated by Torso signaling. We therefore examined whether Cic interacts with Gro in vitro. We expressed in bacteria three different fragments of Cic (amino-terminal, central, and carboxyterminal, see Fig. 5) as GST fusions and assayed their ability to bind radiolabeled Gro protein. The carboxyterminal portion of Cic interacts with Gro, whereas the amino-terminal and central regions of the protein show little or no binding (Fig. 5). The binding of Cic to Gro is weaker than that of Hairy, but stronger than the Dorsal/ Gro interaction in the same assay (Fig. 5). We also find that the interaction of Cic with Gro does not depend on the conserved carboxy-terminal domain of Cic (Fig. 4E; data not shown), indicating that this domain mediates another aspect of Cic function. Taken together, the results support the idea that Cic and Gro form a repressor complex inactivated by Torso signaling during terminal and dorsoventral patterning (see below).

\section{Cic is under negative post-transcriptional regulation by the Torso pathway}

What is the actual target of Tor signal inactivation at the embryonic poles? Previous work has shown that the Drosophila Yan Ets-like repressor factor is degraded in response to RTK signaling during eye development (Rebay and Rubin 1995). Thus, it is possible that the target of Tor signaling is similarly inactivated at the embryo poles. The Gro protein is uniformly distributed in the blastoderm embryo and does not show down-regulation at the termini (Delidakis et al. 1991). Also, Gro corepressor activity during sex determination is not inhibited by 

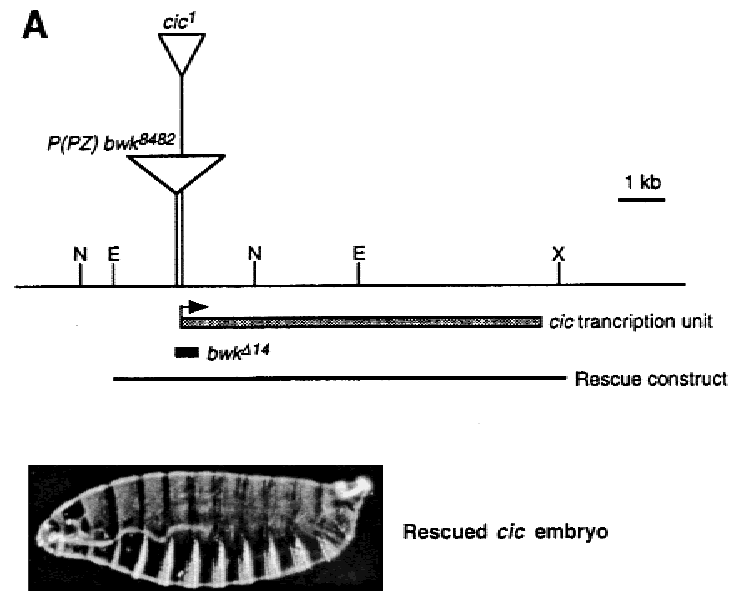

Rescued cic embryo

B

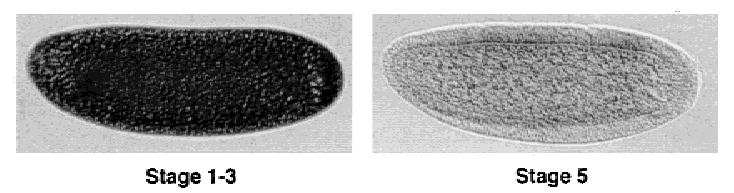

Figure 4. cic encodes an evolutionarily conserved HMG box transcription factor. (A) Diagram of the cic genomic region showing the insertion sites of the hobo element causing the $\mathrm{cic}^{1}$ mutation and the nearby $P(P Z) b w k^{8482} \mathrm{P}$ element (transposons are not represented at scale). The cic transcription unit spans $\sim 8 \mathrm{~kb}$ and includes at least two introns. We have mapped in detail only one intron in the $5^{\prime}$ region of the gene (not shown). The diagram shows the region deleted in a small deficiency caused by imprecise excision of $P(P Z) b w k^{8482}$, $b w k^{\Delta 14}$ (see Materials and Methods), which does not complement $c i c^{1}$. The genomic construct used to rescue the cic phenotype and a rescued embryo are also shown. (E) EcoRI; (N) NotI; (X) XbaI. (B) Maternal expression of cic. cic transcripts accumulate in early blastoderm embryos (stages 1-3) but become undetectable after the onset of gastrulation (stage 5). In situ hybridizations were carried out with an anti-sense cic RNA probe. $(C)$ Amino acid sequence of the deduced Cic protein. The HMG box domain is shown in bold. Possible MAPK phosphorylation sites (P-X-S/T-P) are underlined. Note the presence of multiple homopolymeric stretches in the protein, particularly in the amino-terminal domain. $(D)$ Sequence alignment of HMG box domains from Drosophila Cic (D) and two related proteins from humans $(\mathrm{H}$; GenBank accession no. AB002304) and C. elegans

(C; GenBank accession no. Z50797). Periods indicate identical residues. (E) Sequence alignment of the Cic carboxy-terminal domain (amino acids 1308-1355) with the corresponding region of the human and C. elegans proteins; the strong conservation indicates that these proteins are true orthologs. We have not detected significant similarities outside of the HMG box and carboxy-terminal domains.

Tor signaling, arguing that Gro is not the target of the Tor signal (Paroush et al. 1997). To monitor the pattern of Cic distribution in embryos, we raised a polyclonal antibody against an HMG box-containing fragment of the protein (see Materials and Methods). This antibody revealed a distinctive nuclear signal in wild-type but not cic $^{1}$ blastoderm embryos (Fig. 6A,B), confirming both that Cic is a nuclear protein and that the $c i c^{1}$ allele is a strong loss-of-function mutation. Remarkably, Cic is distributed asymmetrically in blastoderm embryos, be-

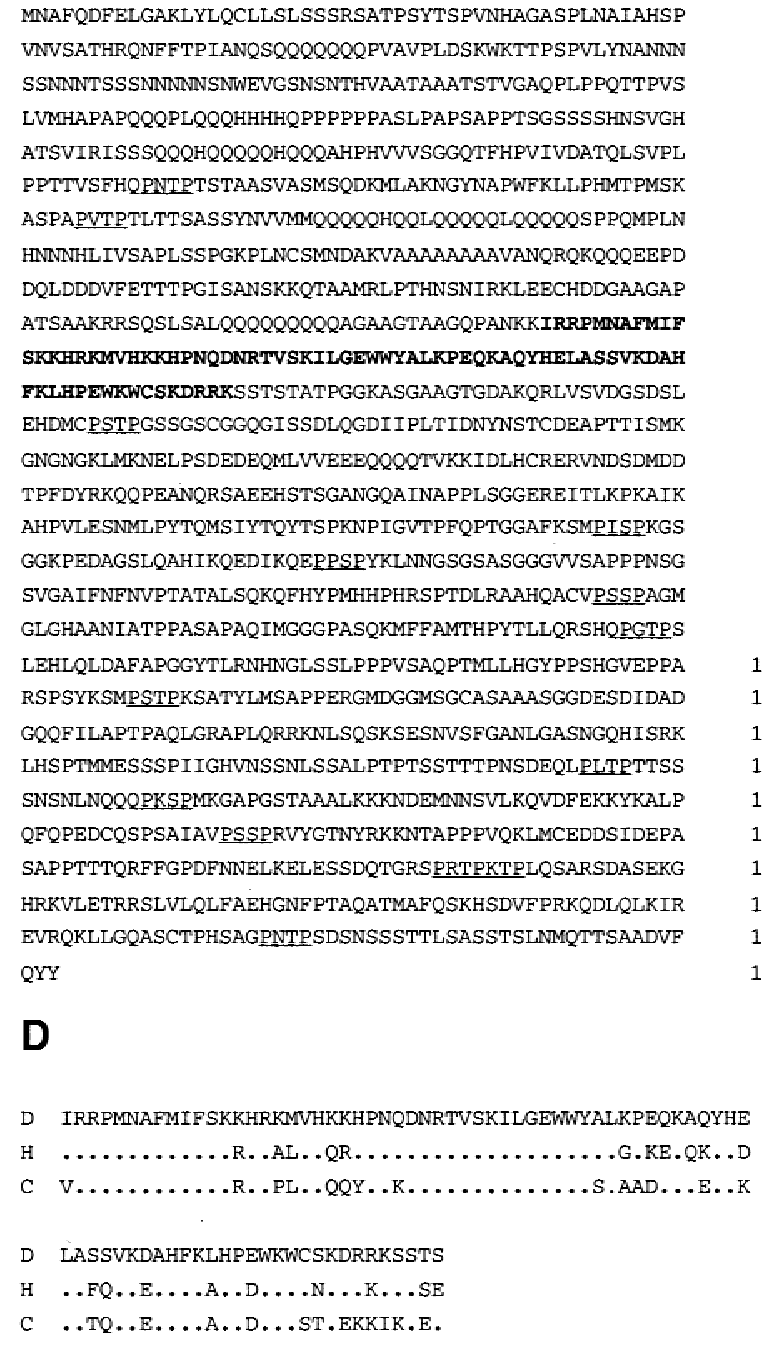

E

D RRSLVLQLFAEHGNFPTAQATMAFQSKHSDVFPRKQDLQLKIREVRQK

H .A..M...QD..F..S...A...ARYA.I..S.VC........

C ..R..ATFLDDQ.L..NNHTINE..EL.KE...TRNA.I......R

列


A

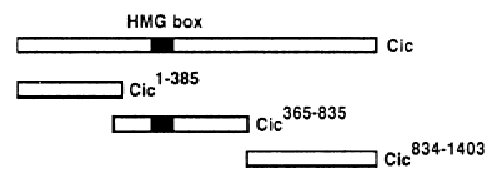

B

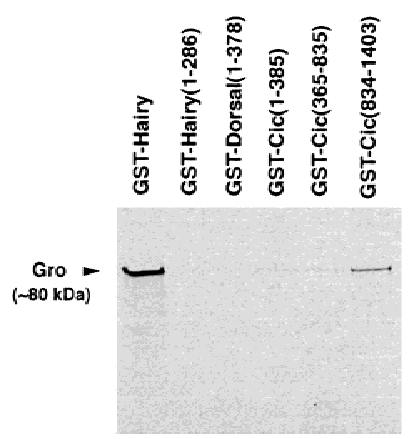

Figure 5. Cic binds to Gro in vitro. (A) Diagram of the Cic protein and three fragments tested for interaction with Gro. $(B)$ ${ }^{35}$ S-labeled Gro was incubated with similar amounts of the indicated GST fusions bound to glutathione-Sepharose beads. After washing the beads, the retained Gro protein was detected by autoradiography. The $\mathrm{Cic}^{834-1403}$ domain binds to Gro, whereas the other two domains show little or no binding. GST fusions of Hairy and Dorsal ${ }^{1-378}$ were used as positive controls (Paroush et al. 1994; Dubnicoff et al. 1997), whereas GST-Hairy ${ }^{1-286}$ (a mutant lacking the carboxy-terminal Gro-binding motif) was the negative control (Jiménez et al. 1997). Binding of Gro to Dorsal ${ }^{1-}$ 378 appears very weak in our assay. We have not observed significant similarities between the $\mathrm{Cic}^{834-1403}$ domain and other Gro-binding motifs.

inhibits accumulation of Cic protein at the embryo poles. These results suggest that Cic is the target inactivated by the Tor signal, possibly via MAPK phosphorylation and subsequent degradation of the protein, as in the case of Yan (Rebay and Rubin 1995). Consistent with this idea, the Cic protein sequence includes 14 consensus MAPK phosphorylation sites (Fig. 4C). Future studies should define the mechanism by which Tor signaling regulates Cic accumulation and the functional domains of the protein involved in this control.

\section{Possible mechanism of Cic action}

How does Cic mediate repression of terminal and dorsoventral genes? Because we have shown that reporter constructs carrying the tll tor-RE and zen VRE are derepressed in cic mutant embryos, the simplest model is that Cic binds to these regulatory elements and recruits Gro for repression of these genes. Consistent with this idea, there are striking similarities between the consensus DNA-binding site for HMG box proteins (Grosschedl et al. 1994) and sequence elements within the tor-RE and VRE known to mediate transcriptional repression (Jiang et al. 1993; Kirov et al. 1993; Liaw et al. 1995). However, although these elements are bound by control HMG box proteins (our unpublished observations), we have not de- tected specific binding of Cic to them. Perhaps Cic has a very low affinity for DNA and/or requires the presence of accessory factors for efficient DNA binding. Several HMG box proteins rely on interactions with partner proteins to increase their affinity for DNA (Kjaerulff et al. 1997; Kamachi et al. 1999). Clearly, identification of the
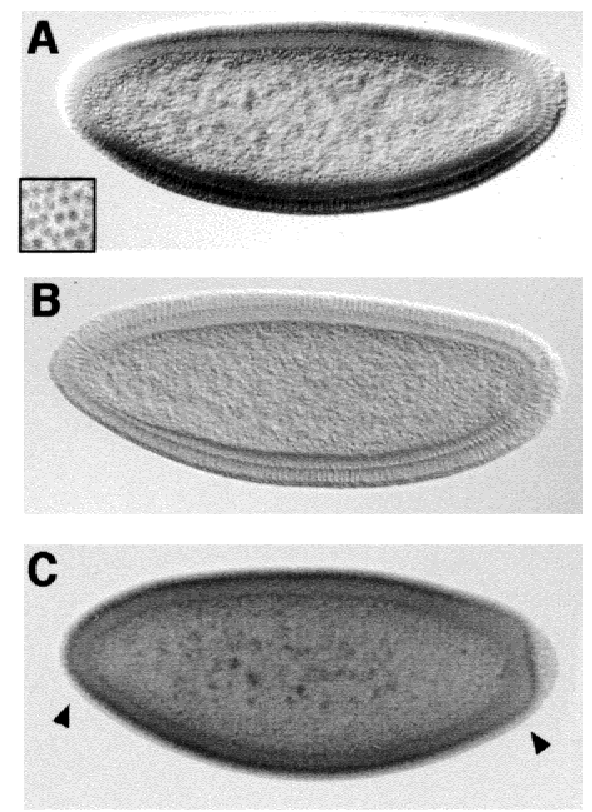

D

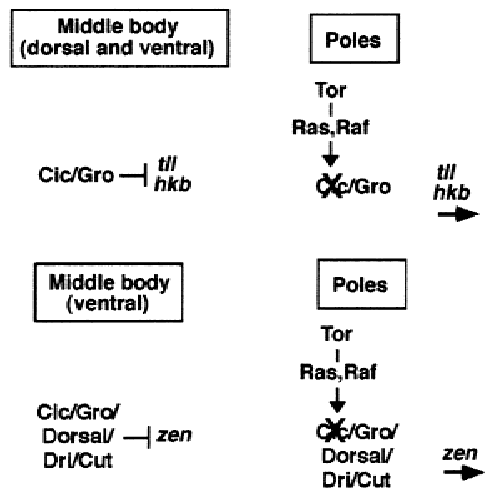

Figure 6. Cic is negatively regulated by the Tor pathway. $(A)$ Pattern of Cic protein distribution in wild-type embryos. The protein localizes predominantly in the nucleus (inset; surface view of blastoderm embryo) and is present in medial but not terminal regions of the embryo. $(B, C)$ Pattern of Cic protein in $\operatorname{cic}^{1}(B)$ and tor mutant embryos $(C)$. Note the lack of staining in the $\mathrm{cic}^{1}$ background, and the accumulation of Cic protein at the poles of tor mutant embryos (arrowheads). (D) Model for Cic function in terminal and dorsoventral patterning. Cic associates with Gro to form a protein complex that represses $t 11$ and $h k b$ expression in the central region of the embryo. The Tor RTK pathway inactivates Cic at the embryo poles, thus allowing activation of $t 11$ and $h k b$ by other maternal factors. A similar mechanism operates in the regulation of zen, except that repression in middle regions of the embryo is only ventral and also requires Dorsal and other corepressors such as Dri and Cut. In both cases, repression could involve additional factors. 
precise molecular mechanism of Cic function will require further analyses of its ability to interact with target sequences in terminal and dorsal-specific genes.

That Cic functions in association with other factors is consistent with previous studies that have implicated several proteins in Gro-dependent repression of terminal and dorsal-specific genes (Liaw et al. 1995; Valentine et al. 1998). For example, it has been shown that Dri and Cut are two of the cofactors required for repression by Dorsal through the zen VRE (Valentine et al. 1998), and our results indicate that Cic also contributes to switching Dorsal from an activator to a repressor of transcription. Similarly, the dramatic effects of Cic on terminal patterning indicate that both Cic and Gro are essential components in the repression of terminal genes. We still do not understand how the activity of all these factors is coordinated in vivo. Nevertheless, our results showing that Cic is under negative post-transcriptional control by the Tor RTK pathway, suggest that it functions as the regulatory element that links Tor signaling to the mechanism of repression (see Fig. 6D).

Finally, the Cic protein has been conserved widely during evolution, being present in organisms as different as C. elegans and humans. Thus, Cic-like proteins may also mediate the formation of multiprotein repressor complexes in other animals, and function as targets of RTK signaling to regulate cellular responses by relief of repression, rather than by direct activation of gene expression.

\section{Materials and methods}

\section{Fly stocks}

The $c i c^{1}$ mutation was isolated in a P-element screen for female-sterile mutations affecting anteroposterior polarity of embryos; the mutation is homozygous viable and $100 \%$ female sterile. Flies carrying the tor-RE-lacZ transgene (construct G22 in Liaw et al. 1995) were kindly provided by J. Lengyel (UCLA). The St.2-1acZ-VRE stock (construct St.2-1acZ-VRE 600; forward orientation) was a gift of H. Cai (University of Georgia, Athens). Germ-line clones of Draf and Dsor were generated with the $D r a f^{L E 78}$ and $D s o r^{1}$ alleles in combination with the $O V O^{D}-F L P$ FRT system (Chou et al. 1993). tor mutant embryos were obtained from homozygous tor ${ }^{X R 1}$ mothers. Imprecise excisions of the $b w k^{8482}$ P-element insertion were recovered as described (Rittenhouse and Berg 1995), and characterized by PCR. For rescue of the $\mathrm{cic}^{1}$ mutation, a genomic EcoRI-XbaI fragment was assembled into $p C a S p e R 4$, and the resulting construct was used to transform $y w$ flies.

\section{Embryo analyses}

Patterns of gene expression were determined by whole-mount in situ hybridization with digoxygenin-labeled DNA $(t 11)$ or RNA (hkb, zen, lacZ, cic) probes. Immunohistochemical detection of Erk and Sxl was performed with monoclonal antibodies against the diphosphorylated form of Erk (Sigma) and the active Sxl protein. For detection of Cic protein, a polyclonal antibody was generated in rabbits by injecting an HMG-box containing fragment of Cic $\left(\mathrm{Cic}^{365-582}\right)$ fused to GST. Signals were detected with appropriate secondary antibodies coupled to alkaline phosphatase (in situ hybridizations) or HRP peroxidase (immunostainings).

\section{Cloning of cic}

cic was mapped to chromosomal position 92D1-2. Several genomic fragments from this region were isolated by plasmid rescue with different P-element insertions in this location. One such fragment recovered from the $P(P Z) b w k^{8482}$ P-element insertion (Rittenhouse and Berg 1995) was found to span the insertion site of a hobo element specific to the $\mathrm{cic}^{1}$ chromosome. Sequencing of this site showed that the hobo element is inserted in the 5' untranslated region of the LD05430 transcript. A second cic cDNA almost identical to the LD05430 clone was isolated by screening an embryonic cDNA library (gift of N. Brown, University of Cambridge, UK).

\section{In vitro binding experiments}

cDNA fragments encoding $\mathrm{Cic}^{1-385}, \mathrm{Cic}^{365-835}$, and $\mathrm{Cic}^{834-1403}$ were cloned into $p G E X 2 T\left(\mathrm{Cic}^{834-1403}\right)$ or $p Z E X\left(\mathrm{Cic}^{1-385}\right.$ and $\mathrm{Cic}^{365-835}$; see Jiménez et al. 1997). Expression of GST fusions in Escherichia coli strain SRP84 and binding assays to radiolabeled Gro protein were carried out as described (Paroush et al. 1994; Jiménez et al. 1997).

\section{Acknowledgments}

We thank N. Martín for technical assistance, S. González-Crespo and J. Bernués for discussions, M. Erdélyi and P. Zavorszky for their help in the genetic screen, C. Berg, M. Levine, H. Cai, J. Lengyel, and Y. Kamachi for fly stocks and DNA clones and S. González-Crespo, A. González-Reyes, E. Sánchez-Herrero, and G. Morata for comments on the manuscript. G.J. is supported by a contract from the Spanish Ministerio de Educación y Cultura (MEC). A.G. was supported by fellowships from the Ministère de la Recherche et du Travail and the EMBL. This work was funded by the Spanish MEC and the Generalitat de Catalunya (C.R. Biotecnologia).

The publication costs of this article were defrayed in part by payment of page charges. This article must therefore be hereby marked "advertisement" in accordance with 18 USC section 1734 solely to indicate this fact.

\section{Note added in proof}

The EMBL accession no. for the cic cDNA sequence is AJ252268.

\section{References}

Brunner, D., N. Oellers, J. Szabad, W.H. Biggs, S.L. Zipursky, and E. Hafen. 1994. A gain of function mutation in Drosophila MAP kinase activates multiple receptor tyrosine kinase signalling pathways. Cell 76: 875-888.

Cai, H.N., D. Arnosti, and M. Levine. 1996. Long-range repression in the Drosophila embryo. Proc. Natl. Acad. Sci. 93: 9309-9314.

Casanova, J. 1991. Interaction between torso and dorsal, two elements of different transduction pathways in the Drosophila embryo. Mech. Dev. 36: 41-45.

Cavallo, R.A., R.T. Cox, M.M. Moline, J. Roose, G.A. Polevoy, H. Clevers, M. Peifer, and A. Bejsovec. 1998. Drosophila Tcf and Groucho interact to repress Wingless signalling activity. Nature 395: 604-608.

Chou, T.B., E. Noll, and N. Perrimon. 1993. Autosomal P[ovoD1] dominant female-sterile insertions in Drosophila and their use in generating germ-line chimeras. Development 119: 1359-1369.

Delidakis, C., A. Preiss, D.A. Hartley, and S. Artavanis-Tsako- 
nas. 1991. Two genetically and molecularly distinct functions involved in early neurogenesis reside within the Enhancer-of-split locus of Drosophila melanogaster. Genetics 129: 803-823.

Dubnicoff, T., S.A. Valentine, G. Chen, T. Shi, J.A. Lengyel, Z. Paroush, and A.J. Courey. 1997. Conversion of Dorsal from an activator to a repressor by the global corepressor Groucho. Genes \& Dev. 11: 2952-2957.

Duffy, J.B. and N. Perrimon. 1994. The Torso pathway in Drosophila: Lessons on receptor tyrosine kinase signaling and pattern formation. Dev. Biol. 166: 380-395.

Fisher, A.L. and M. Caudy. 1998. Groucho proteins: Transcriptional corepressors for specific subsets of DNA-binding transcription factors in vertebrates and invertebrates. Genes \& Dev. 12: 1931-1940.

Gabay, L., R. Seger, and B.-Z. Shilo. 1997. MAP kinase in situ activation atlas during Drosophila embryogenesis. Development 124: 3535-3541.

Grosschedl, R., K. Giese, and J. Pagel. 1994. HMG domain proteins: Architectural elements in the assembly of nucleoprotein structures. Trends Genet. 10: 94-100.

Jiang, J., H. Cai, Q. Zhou, and M. Levine. 1993. Conversion of a dorsal-dependent silencer into an enhancer: Evidence for dorsal corepressors. EMBO J. 12: 3201-3209.

Jiménez, G., Z. Paroush, and D. Ish-Horowicz. 1997. Groucho acts as a corepressor for a subset of negative regulators, including Hairy and Engrailed. Genes \& Dev. 11: 3072-3082.

Kamachi, Y., K.S.E. Cheah, and H. Kondoh. 1999. Mechanism of regulatory target selection by the Sox High-Mobility-Group domain proteins as revealed by comparison of Sox $1 / 2 / 3$ and Sox9. Mol. Cell. Biol. 19: 107-120.

Kirov, N., L. Zhelnin, J. Shah, and C. Rushlow. 1993. Conversion of a silencer into an enhancer: Evidence for a co-repressor in dorsal-mediated repression in Drosophila. EMBO J. 12: 3193-3199.

Kjaerulff, S., D. Dooijes, H. Clevers, and O. Nielsen. 1997. Cell differentiation by interaction of two HMG-box proteins: Mat1-Mc activates $M$ cell-specific genes in $S$. pombe by recruiting the ubiquitous transcription factor Ste11 to weak binding sites. EMBO J. 16: 4021-4033.

Klinger, M., M. Erdélyi, J. Szabad, and C. Nüsslein-Volhard. 1998. Function of torso in determining the terminal anlagen of the Drosophila embryo. Nature 335: 275-277.

Liaw, G., K.M. Rudolph, J.-D. Huang, T. Dubnicoff, A.J. Courey, and J.A. Lengyel. 1995. The torso response element binds GAGA and NTF-1/Elf-1, and regulates tailless by relief of repression. Genes \& Dev. 9: 3163-3176.

Parkhurst, S.M. 1998. Groucho: Making its Marx as a transcriptional co-repressor. Trends Genet. 14: 130-132.

Paroush, Z., R.L.J. Finley, T. Kidd, S.M. Wainwright, P.W. Ingham, R. Brent, and D. Ish-Horowicz. 1994. Groucho is required for Drosophila neurogenesis, segmentation and sexdetermination, and interacts directly with Hairy-related bHLH proteins. Cell 79: 805-815.

Paroush, Z., S.M. Wainwright, and D. Ish-Horowicz. 1997. Torso signalling regulates terminal patterning in Drosophila by antagonizing Groucho-mediated repression. Development 124: 3827-3834.

Rebay, I. and G.M. Rubin. 1995. Yan functions as a general inhibitor of differentiation and is negatively regulated by activation of the Ras1/MAPK pathway. Cell 81: 857-866.

Rittenhouse, K.R. and C.A. Berg. 1995. Mutations in the Drosophila gene bullwinkle cause the formation of abnormal eggshell structures and bicaudal embryos. Development 121: 3023-3033.

Roose, J., M. Molenaar, J. Peterson, J. Hurenkamp, H. Brantjes,
P. Moerer, M. van de Wetering, O. Destrée, and H. Clevers. 1998. The Xenopus Wnt effector XTcf-3 interacts with Groucho-related transcriptional repressors. Nature 395: 608-612.

Rusch, J. and M. Levine. 1994. Regulation of the dorsal morphogen by the Toll and torso signaling pathways: A receptor tyrosine kinase selectively masks transcriptional repression. Genes \& Dev. 8: 1247-1257.

. 1996. Threshold responses to the dorsal regulatory gradient and the subdivision of primary tissue territories in the Drosophila embryo. Curr. Opin. Gen. Dev. 6: 416-423.

Tsuda, L., Y.H. Inoue, M.-A. Yoo, M. Mizuno, M. Hata, Y.-M. Lim, T. Adachi-Yamada, H. Ryo, Y. Masamune, and Y. Nishida. 1993. A protein kinase similar to MAP kinase activator acts downstream of the Raf kinase in Drosophila. Cell 72: 407-414.

Valentine, S.A., G. Chen, T. Shandala, J. Fernández, S. Mische, R. Saint, and A.J. Courey. 1998. Dorsal-mediated repression requires the formation of a multiprotein repression complex at the ventral silencer. Mol. Cell. Biol. 18: 6584-6594.

Weigel, D., G. Jürgens, M. Klinger, and H. Jäckle. 1990. Two gap genes mediate maternal terminal pattern formation in Drosophila. Science 248: 495-498. 


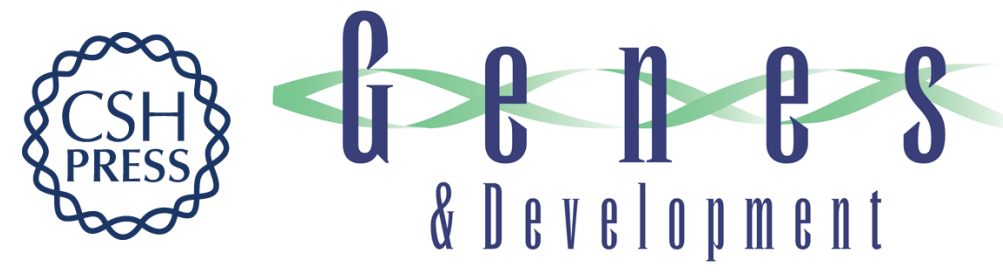

\section{Relief of gene repression by Torso RTK signaling: role of capicua in Drosophila terminal and dorsoventral patterning}

Gerardo Jiménez, Antoine Guichet, Anne Ephrussi, et al.

Genes Dev. 2000, 14:

Access the most recent version at doi:10.1101/gad.14.2.224

References This article cites 29 articles, 15 of which can be accessed free at: http://genesdev.cshlp.org/content/14/2/224.full.htmI\#ref-list-1

License

Email Alerting

Receive free email alerts when new articles cite this article - sign up in the box at the top Service right corner of the article or click here.

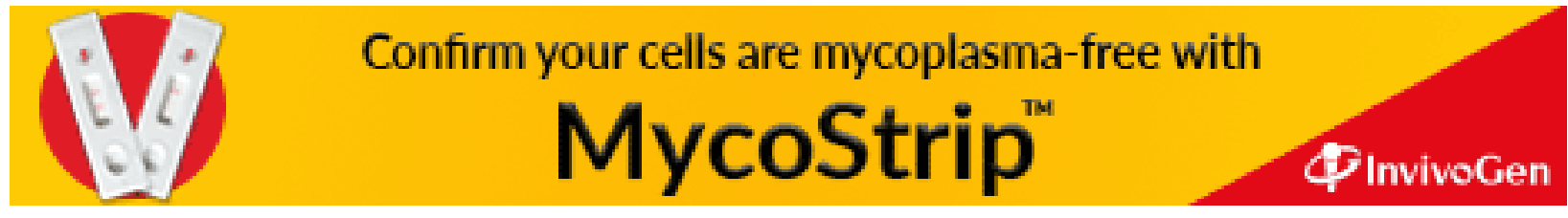

